\title{
Nuevas miradas sobre el proyecto en indumentaria en Latinoamérica: el pensamiento sobre el objeto, tradiciones y rupturas conceptuales
}

\section{Fiorini, Verónica [ver currículum del autor, docente de la Facultad de Diseño y Comunicación]}

Resumen:

Repensar los productos básicos de diseño nos obliga a revisar los cambios en los modos del proyecto. Nuevos enfoques sobre la producción, las metodologías y las estrategias de pensamiento puestas en juego en los procesos de enseñanza del diseño de indumentaria suponen diversas reflexiones disciplinares. Estos aspectos se enlazan de modo indisoluble con los nuevas modalidades de consumo en las que se presenta un diálogo entre lo local y lo global (Morace).La preocupación ligada a la sustentabilidad del diseño convive en el campo de la moda, aunque todavía es objetivado como un sistema de innovación permanente (Barthes). El sentido del gusto

(Bourdieu), las preferencias o inclinaciones desde la óptica sociocultural y de una creciente conciencia ambiental por parte de los diseñadores y docentes del proyecto, se ponen en juego en los aspectos conceptuales del diseño, desplegando tensiones, diálogos y relaciones que este trabajo se propone recorrer en un sentido abarcativo.

Palabras clave:

Nuevas visiones del proyecto - didáctica - metodologías - consumo - tendencias - global - local - sustentabilidad innovación - moda.

Introducción
Cuadernos del Centro de Estudios de Diseño y Comunicación Nº 64

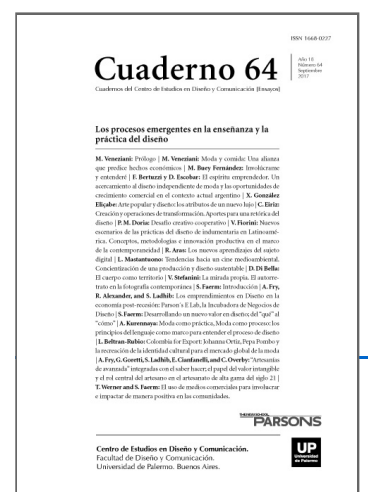

ISSN: 1668-0227

Los procesos

emergentes en la

enseñanza y la

práctica del diseño

Año XVIII, Septiembre 2017, Buenos

Aires, Argentina | 326 páginas

descargar PDF

ver índice de la publicación

Ver todos los libros de la publicación

compartir en Facebook

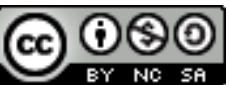

Esta obra está bajo una Licencia Creative Commons Atribución-NoComercialCompartirlgual 4.0 Internacional 
Repensar los productos básicos de diseño nos obliga a revisar ciertos cambios conceptuales ligados a los modos de concreción de los proyectos de moda. Uno de los objetivos de este trabajo será interpelar algunos enfoques sobre metodología, producción e investigación que se ponen en juego en la enseñanza del diseño de indumentaria. Dichos aspectos se enlazan de modo indisoluble con algunos debates históricos inscriptos en la Modernidad y que cobran vigencia en la Modernidad tardía. El Sistema de la Moda, con su inherente espíritu efímero es cuestionado de modo creciente, y la problemática comunicacional se vuelve ineludible a la hora de abordar cuestiones propias del campo disciplinar, como la generación de nuevos productos básicos y nuevos valores vinculados al diseño.

\section{El pensamiento sobre el objeto moderno y contemporáneo}

En el presente trabajo se intenta ahondar en ciertos abordajes que han marcado profundamente la enseñanza del diseño industrial y de indumentaria en el marco de la modernidad y posmodernidad. Estos preceptos, lejos de haber sido investigados a fondo, actualizan nuevos enfoques sobre la proyectación de los sistemas vestimentarios. En la modernidad tardía se presentan cambios socioculturales que complejizan las prácticas del diseño y el rol del diseñador de indumentaria. Aspectos de género, edad, identidades culturales y ambientales obligan a reformular las visiones tradicionales del campo disciplinar y de la enseñanza del diseño de moda. En este contexto, los nuevos valores asociados a los productos básicos, deben ser interpelados a la luz de ciertas líneas teóricas que atraviesan las concepciones del diseño en su dimensión histórico social. Entonces la pregunta esencial no es, solamente, como serán los nuevos productos básicos, sino como serán concebidos, pensados y proyectados. Las metodologías de diseño deben ser repensadas en un marco de complejidad comunicacional, ambiental y económica creciente en un mundo globalizado y cambiante. En este sentido, este trabajo intenta validar los siguientes interrogantes: ¿Cuáles son las influencias de la Modernidad que aún hoy determinan algunas concepciones del diseño en relación a los modos de generación de los denominados productos básicos? ¿Qué aspectos de la Modernidad tardía replantean algunos de esos supuestos heredados de las concepciones modernas del diseño? En unos de los diez principios del buen diseño industrial que enuncia Dieter Rams (1970), se propone como imperativo la idea de que el objetivo primordial de un objeto es su utilidad y que los aspectos estéticos-formales o vinculados a la psicología debieran estar en un segundo plano y no distorsionar su eficacia. Como otra pauta clave, este autor indica que el objeto debe comunicar su función al usuario y que debe ser discreto y sobrio en sus formas. También propugna la idea de que los objetos se mantengan alejados de la decoración y del arte (en este aspecto coincide con A. Loos) y cercanos a la función de herramientas. Términos como discreto, honesto, preciso, detallista en su mínima expresión, puro y simple, demuestran la claridad programática y la potencia del discurso moderno atravesando de manera profunda e innegable el campo del diseño objetual como una marca de fuego. Un caso emblemático precedente dentro del campo de la moda, es C. Chanel (1920) a principios del siglo XX, como un ejemplo fiel de este modo de concebir los objetos vestimentarios con una impronta funcionalista. Lo cierto en que en el planteo de Dieter Rams (1970) se elude el trasfondo ideológico y simbólico del método de diseño propuesto y de su práctica a la manera del habitus de P. Bourdieu (2010, p. 14). Es decir que la idea de utilidad se presenta naturalizada y en este sentido podemos afirmar que también en el concepto de "producto básico" anida una raíz similar. Lo básico aparece, etimológicamente como fundamental, como lo indispensable. Para ampliar este enfoque, J. Baudrillard (1974) nos demuestra que se establece un "engaño", se naturaliza la idea de que se produce lo que se necesita, lo que es útil, y así ve al funcionalismo, como una estrategia más del sistema que deviene fin en sí mismo. Desde el punto de vista moderno, esta idea de dividir o imaginar la tarea del diseñador dividiendo imaginariamente lo 
importante de lo no importante, lo útil de lo inútil, lo ornamental de lo esencial, es seriamente criticada y puesta en crisis por otros autores de la modernidad tardía como R. Buchanan (1992). Lo que R. Buchanan (1992) nos presenta es un contexto con multiplicidad de aspectos y variables, en donde la práctica del diseño no puede transitar de modo alguno un proceso simple y lineal por un sencillo motivo: los problemas de diseño son complejos y ambiguos. Por este motivo, R. Buchanan propone concebir desde una mirada contemporánea, a esta práctica como una disciplina integrativa (artes y ciencias) y hacer una crítica fundada en la metodología del modelo solving problems. En esta metodología, de esencia moderna, existe una fase analítica de definición del problema y una fase sintética que brinda la solución para esa necesidad. Las falencias subrayadas por R. Buchanan (1992) son la linealidad funcionalista y la idea que Horst Rittel (1992) denomina los problemas perversos del diseño, indeterminados y ambiguos. También rebate el concepto universalista del diseño moderno al advertir que el diseño concierne de manera inequívoca a "lo particular". Rechaza la idea de reducir el pensamiento de diseño a la forma de un objeto/producto y advierte la importancia de un contexto indeterminado como condición recurrente para el plan de proyectar aquello que no tiene una definición a priori. Cuando Buchanan plantea que la historia del diseño no debe ser una historia del objeto sino de las miradas y enfoques sobre los temas de estudio está advirtiendo de manera lúcida el rastro del 'habitus'1 del diseño en el sentido de P. Bourdieu (2010, pp. 14-15). En esta línea teórica, se puede inferir que la idea de pensar en productos básicos requiere que los estudiantes se pregunten acerca de la definición misma del término e incluso de su propia metodología. Un ejemplo de esta problemática es la idea misma de sostenibilidad en la moda. Al ser interrogados, los estudiantes arriban la mayoría de las veces a la idea de que lo que merece ser revisado no es un producto, su manera de reproducción o su posterior uso, sino la idea misma de obsolescencia planificada que plantea el Sistema de la Moda identificada por R. Barthes (2003). Es decir que el razonamiento profundo frente a los productos efímeros de producción seriada del Sistema de la Moda, aparece con un sentido crítico que sugiere repensar las bases mismas del diseño y su reproducción.

Sostenibilidad y globalización del consumo de la moda

Para Kate Fletcher y Linda Grose (2012) uno de los problemas es que "la mayoría de los artefactos modernos tienen procedencia internacional, pues se elige la ruta de producción más económica para cada etapa del proceso y para cada componente". Este aspecto de una producción globalizada tendría aspectos problemáticos respecto a la sostenibilidad de la indumentaria, debido a los impactos sociales, culturales y ecológicos implícitos en estas prácticas. En relación a estos temas, se pone en jaque la idea de escala y producción fuera de la región de consumo de los productos. En este sentido es posible afirmar que diseñar nuevos básicos dentro del campo de la moda exigirá el gran desafío de trabajar de manera local, en relación a los materiales y procesos pero también tendrán que poner en valor las identidades locales en diálogo franco con la comunidad global. El foco será cada vez más la combinación del diseño de indumentaria conectada a experiencias valiosas, cargadas de sentido y valor simbólico pero en articulación con un pensamiento agudo respecto al impacto socio-ambiental. Desde otro ángulo, como otro aspecto complejo de la disciplina, surge un concepto fuerte en torno a la calidad. La idea de calidad ligada a los productos básicos también se ve atravesada por los siguientes ejes:

- Diseño y calidad conceptual: los imaginarios vinculados a los usuarios y su conexión con las tendencias socioculturales de consumo se vuelven determinantes en la fase investigativa del proyecto. Un producto básico innovador debe indagar en la mente de los consumidores, detectando motivaciones, usos y relaciones con los diferentes objetos de la vida cotidiana y con la sotras personas. - Diseño y calidad ambiental: La sustentabilidad como parte natural del proyecto de indumentaria, se mimetizará con las distintas propuestas estéticas y 
comunicacionales. Se indagarán nuevos modos de proyectar diseño sostenible más allá de la materialidad, procesos, reusos y co-design. El diseño sostenible deberá encontrar modos de integrarse y redefinir el Sistema de la Moda con nuevas lógicas temporales a largo plazo2. Es decir que el contexto contemporáneo de creciente conciencia ambiental se vuelve crucial en las distintas etapas de diseño.

En cambio, la idea de proyecto moderno que se propone en el decálogo de D. Rams (1970), que es opuesta a la de R. Buchanan (1992), el contexto no parece ser un eje fundamental del diseño y los programas son planteados en base a necesidades autónomas, concretas, mensurables, definidas y calculadas. Rams distingue: "De un lado la disciplina de la simplicidad. Del otro, expresión forzada, opresiva y estupidizante". Estas propuestas dicotó- micas entre lo racional y lo irracional (lo útil y lo inútil) nos demuestran la necesidad de construir un discurso en la que los objetos existen por una razón primordial: la utilidad en la unión forma-función. Rams (1970) rechaza la idea de un diseño vinculado a los cambios del gusto, ausente del sentido del uso y con significados triviales o superficiales. En forma opuesta, Baudrillard $(1969,1974)$ incluye todas las variantes del gusto y los cambios en la moda como pilar estructurante de otras prácticas sociales, en las antípodas de la trivialidad. Funcionalismo y styling (como versión de la obsolescencia de la moda) son dos caras de una misma moneda. Uno vale por la existencia del otro. La mirada estructuralista le permite avanzar en este sentido. Para Baudrillard (1974) el objeto de consumo no existe en sí mismo sino como mito resultante de diferentes tipos de relaciones y de significaciones que vienen a anudarse sobre él en tanto que tal. Más allá d ella funiconalidad del objeto: "La libertad de elegir que tenemos nos obliga a entrar en el sistema cultural" (1969, p. 157).

En cuanto a la práctica del diseño, se pueden inferir tres visiones diferenciadas. En la mirada funcionalista, para A. Moles (1971) se visualiza la interacción del hombre con el ambiente en una transacción que domina a este último. Para Baudrillard (1974), ciertamente el rol del diseñador es desde una óptica profundamente pesimista, ser un engranaje más del sistema político e ideológico de la sociedad posmoderna. Finalmente, para R. Buchanan (1992), el diseñador es quién puede establecer argumentos retóricos a través de sus producciones (no cosméticos, para la persuasión pura) en forma activa, es decir ser un verdadero agente de la comunicación y por consiguiente es alguien que puede modificar la cultura contemporánea. Esta última postura creemos que revaloriza la disciplina del diseño postulando al diseñador como un agente conceptual y ya no como un mero hacedor de objetos y mensajes.

\section{Deconstruyendo el habitus del diseño}

En síntesis, puede afirmarse que J. Baudrillard (1974) deconstruye nociones clásicas del paradigma moderno: objeto, necesidad y valor de uso son repensados en su misma esencia. Para este autor, en definitiva el verdadero sentido del término "funcional" es ser adaptable a un sistema de signos (no valen en sí mismos, en esto coincide con una mirada estructuralista). En A. Moles (1971), se advierte no sólo la genealogía del kitsch en los objetos sino del funcionalismo como reacción rupturista de quiebre con los diseños precedentes por lo que se comprende que no es un fenómeno aislado en la historia, sino más bien una continuidad de las contradicciones modernas. R. Buchanan (1992) descentra el problema de los objetos de la función y de la forma material: signos, cosas, acciones y pensamientos definen a la práctica del diseño. Para este autor nuevas preguntas e ideas son las que pueden modificar el campo disciplinar y redefinirlo conceptualmente superando la visión reduccionista de la profesión de los diseñadores como la de meros artífices formales. Algunos de estos interrogantes le son adjudicados al diseño posmoderno y a la deconstrucción formal en tanto cuestionan las viejas categorías o tradiciones del campo. El enfrentamiento conceptual entre el pensamiento moderno fundacional del diseño, lí- 
neas conceptuales divergentes de los años 60', y la filosofía posmoderna o posestructuralista de fines de los 70' en adelante hasta la contemporaneidad, se desarrolla en el campo del diseño del siglo XXI materializando un juego de fuerzas en donde se disputa la verdadera naturaleza de lo proyectual en tanto quehacer generador de objetos y productos. Los textos que han sido abordados y puestos en relación dan prueba fiel de esta contienda de ideas que recorre el panorama histórico del diseño en general. Los aportes de los textos de A. Moles (1971), J. Baudrillard (1974), R. Buchanan (1992) y K. Fletcher (2012), constituyen justamente intentos que permiten deconstruir el habitus del diseño y de la generación de objetos para repensar las lógicas sociales y también los contextos complejos en las que está inserta la práctica del proyecto del diseño. Tanto la mirada funcionalista como la visión del styling del producto se presentan a la vez en tensión en la modernidad argumentando posturas de diseño. Cuando se habla de productos básicos, de modo implícito surgen interrogantes: que comunican y en que contexto, para qué y quién los utilizará, como serán producidos, que ocurrirá con ellos luego de su uso. A la luz de todo lo expuesto anteriormente, podemos inferir que estas preguntas devienen de algunas tradiciones del campo del diseño, lejos de ser interrogantes aislados, nos demuestran que conviven concepciones del pasado con verdaderas miradas a futuro. Para K. Fletcher y L. Grose (2012, p. 155):

El diseño se encuentra en un punto de inflexión, en el que las grandes fuerzas ecológicas, socioculturales y económicas están obligando a la industria a revisar los sistemas de valor que imperan en el diseño y las aplicaciones tradicionales de éste.

Para concluir, podemos decir que desde este enfoque quedan expuestos algunos aspectos de una problemática disciplinar. Esto exige deconstruir los modos habituales de pensar, proyectar, y llevar a cabo las prácticas del diseño de indumentaria. De igual modo, exige problematizar las estrategias didácticas tradicionales ligadas a la enseñanza del proyecto a la hora de imaginar aquello que será un nuevo producto básico. Este artículo, lejos de agotar está temática, pretende ampliar un abanico de interrogantes para futuros trabajos del campo de la moda.

Notas

1. La noción de habitus de Pierre Bourdieu (1970) es entendida como esquemas que ligan los modos d eobrar, pensar y sentir a una posición social. A partir de los mismos los sujetos perciben el mundo y actúan en él. 2. Kate Fletcher y Lynda Grose (2012, p. 181) plantean que el diseño de moda estará determinado en el futuro por el impacto ambiental en lugar de por las microtendencias.

\section{Bibliografía}

Fletcher, K. y Grose, L. (2012). Como gestionar la sostenibilidad en la moda. Diseñar para cambiar materiales, procesos, distribución, consumo. Barcelona: Editorial Blume. Barthes, R. (2003). El Sistema de la Moda y otros escritos. Buenos Aires: Editorial Paidós. Bourdieu, P. (2010). El sentido social del gusto.Elementos para una sociología de la cultura. Buenos Aires: Editorial siglo veintiuno. Rams, D. (1970). Los diez principios del buen diseño. Baudrillard, J. (1974). Economía política del signo. Buenos Aires: Siglo XXI editores. Baudrillard, J. (1969). El sistema de los objetos. Buenos Aires: Siglo XXI editores. Buchanan, R. (1992). Problemas perversos del diseño. Londres: The Open University Press. Moles, A. (1971/ 1990). El kitsch (1a. reimpresión). España: Ediciones Paidos. Pevsner, N. (2003). Pioneros del diseño moderno. De William Morris a Walter Gropius (4a. ed.). Buenos Aires: Ediciones Infinito. 
Baudrillard, J. (1970). El sistema de los objetos. México: Siglo XXI.

Abstract:

Us to examine how products are produced. New approaches in production methodologies and thinking strategies at play in the teaching of fashion design involve various disciplinary reflections. These aspects are linked indissolubly with new consumption patterns in which a dialogue between the local and the global can be identified (Morace). The concern about design sustainability is present in the field of fashion, although it is still objectified as a system of continuous innovation (Barthes). The sense of taste (Bourdieu), preferences, or inclinations from the socio-cultural perspective and growing environmental awareness on the part of designers and teachers of the project, are put into play in the conceptual design, unfolding tensions, dialogue, and relationships that this paper intends to analyze.

Key words:

new project approaches - Didactics - methodologies - consumption - trends - global - local - sustainability innovation - fashion.

\section{Resumo:}

Re-pensar os produtos básicos de design obriga a revisar as mudanças nos modos do projeto de design. Novos enfoques sobre a produção, as metodologias e as estraté- gias de pensamento intervenientes nos processos de ensino do design de indumentária supõem diversas reflexões disciplinares. Estes aspectos se vinculam indissoluvelmente com as novas modalidades de consumo onde se apresenta um diálogo entre o local e o global (Morace). A preocupação ligada à sustentabilidade do design convive no campo da moda, embora ainda é objetivado como um sistema de inovação permanente (Barthes). O sentido do gosto (Bourdieu), as preferências ou inclinações desde a óptica sociocultural e de uma crescente consciência ambiental dos designers, exibindo tensões, diálogos e relações que este trabalho propõe percorrer.

Palavras chave:

novas visões do projeto - didática - metodologias - consumo - tendências - global - local - sustentabilidade inovação - moda.

Nuevas miradas sobre el proyecto en indumentaria en Latinoamérica: el pensamiento sobre el objeto, tradiciones y rupturas conceptuales fue publicado de la página 99 a página105 en Cuadernos del Centro de Estudios de Diseño y Comunicación Nº 64 